Gut and Liver, Vol. 9, No. 3, May 2015, pp. 346-352

\title{
Helicobacter pylori Eradication within 120 Days Is Associated with Decreased Complicated Recurrent Peptic Ulcers in Peptic Ulcer Bleeding Patients
}

\author{
Shen Shong Chang, ${ }^{,+, \neq}$and Hsiao-Yun $\mathrm{Hu}^{\mathrm{s}, \|}$ \\ ${ }^{*}$ Division of Gastroenterology, ${ }^{\dagger}$ Department of Internal Medicine, Taipei City Hospital Yang-Ming Branch, ${ }^{*}$ School of Medicine, National Yang- \\ Ming University, ${ }^{s}$ Department of Education and Research, Taipei City Hospital, and "Institute of Public Health and Department of Public Health, \\ National Yang-Ming University, Taipei, Taiwan
}

See editorial on page 259.

Background/Aims: The connection between Helicobacter pylori and complicated peptic ulcer disease in peptic ulcer bleeding (PUB) patients taking nonsteroidal anti-inflammatory drugs has not been established. In this study, we sought to determine whether delayed $H$. pylori eradication therapy in PUB patients increases complicated recurrent peptic ulcers. Methods: We identified inpatient PUB patients using the Taiwan National Health Insurance Research Database. We categorized patients into early (time lag $\leq 120$ days after peptic ulcer diagnosis) and late $H$. pylori eradication therapy groups. The Cox proportional hazards model was used. The primary outcome was rehospitalization for patients with complicated recurrent peptic ulcers. Results: Our data indicated that the late $H$. pylori eradication therapy group had a higher rate of complicated recurrent peptic ulcers (hazard ratio [HR], 1.52; $p=0.006$ ), with time lags of more than 120 days. However, our results indicated a similar risk of complicated recurrent peptic ulcers (HR, 1.20; $p=0.275)$ in time lags of more than 1 year and (HR, 1.10; $p=0.621$ ) more than 2 years. Conclusions: $H$. pylori eradication within 120 days was associated with decreased complicated recurrent peptic ulcers in patients with PUB. We recommend that $H$. pylori eradication should be conducted within 120 days in patients with PUB.

(Gut Liver 2015;9:346-352)

Key Words: Helicobacter pylori; Peptic ulcer hemorrhage; Delayed; Eradication

\section{INTRODUCTION}

Peptic ulcer bleeding (PUB) is the most common complication associated with peptic ulcer disease, and is the major cause of morbidity and mortality in patients with peptic ulcers. ${ }^{1}$ Understanding the role of Helicobacter pylori in the pathogenesis of PUB is crucial to the prevention of life-threatening uppergastrointestinal hemorrhage. Approximately 85\% to 95\% of duodenal ulcer patients and up to 70\% of gastric ulcer patients have concurrent $H$. pylori infections. ${ }^{2,3}$ It is well-recognized that $H$. pylori eradication therapy can reduce the recurrence of peptic ulcer. Hopkins et al. ${ }^{4}$ reported that the recurrence of peptic ulcers can be reduced from $70 \%$ to $10 \%$ or less following $H$. pylori eradication. However, acute PUB patients frequently test negative $H$. pylori infection, ${ }^{5,6}$ and Gisbert and Abraira ${ }^{7}$ reported that between 30\% and 50\% of PUB patients had false-negative results for $H$. pylori diagnostic testing. Moreover, false-negative test results contribute to delays in the initiation of $H$. pylori eradication therapy in many PUB patients.

Nonsteroidal anti-inflammatory drugs (NSAIDs) use is a risk factor of complicated peptic ulcer disease ${ }^{8,9}$ and the most common cause of $H$. pylori negative peptic ulcers. ${ }^{10}$ However, the connection between $H$. pylori and complicated peptic ulcer disease in PUB patients taking NSAIDs remains unclear and divergent. We want to explore whether delayed $H$. pylori eradication therapy in PUB patients increases the risk of complicated recurrent peptic ulcers with hemorrhages and/or perforations.

We selected patients who were endoscopically diagnosed with PUB and hospitalization in Taiwan between 2000 and 2010 from the National Health Insurance Research Database (NHIRD). Based on the date of their treatment, participants were assigned

Correspondence to: Hsiao-Yun Hu

Department of Education and Research, Taipei City Hospital, No.145, Zhengzhou Rd., Taipei 103, Taiwan

Tel: +886-2-27093600 (\#3816), Fax: +886-2-28261002, E-mail: hyhu@ym.edu.tw

Received on December 16, 2013. Revised on January 24, 2014. Accepted on January 28, 2014. Published online on June 18, 2014 pISSN 1976-2283 eISSN 2005-1212 http://dx.doi.org/10.5009/gnl13451

@ This is an Open Access article distributed under the terms of the Creative Commons Attribution Non-Commercial License (http://creativecommons.org/licenses/by-nc/3.0) which permits unrestricted non-commercial use, distribution, and reproduction in any medium, provided the original work is properly cited. 
to an early or a late $H$. pylori eradication therapy group. We compared the clinical outcomes between the study groups to determine whether delayed $H$. pylori eradication therapy in PUB patients increased rehospitalization for the risk of complicated recurrent peptic ulcers.

\section{MATERIALS AND METHODS}

\section{Data source}

Our nationwide cohort study was based on patient data obtained from the NHIRD, which is managed by the National Health Research Institute (NHRI). The NHIRD contains outpatient and inpatient claim records from the National Health Insurance (NHI) system of Taiwan, which provides coverage for approximately 23 million residents (99\% of the population) of Taiwan. ${ }^{11}$ The NHIRD files contain comprehensive health care and enrollment information for a randomly selected sample of one million NHI beneficiaries, representing approximately 5\% of all enrollees in 2000. The diagnoses codes used in the NHI data were based on the International Classifications of Diseases, Revision 9, Clinical Modification (ICD-9-CM). Our study was approved by the NHRI. The Institutional Review Board (IRB) of Taipei City Hospital approved this study (IRB number: TCHIRB1020424-E).

\section{Participant selection}

We conducted a retrospective cohort study of patient records from January 1, 2000 to December 31, 2010. Based on inpatient discharge records, the PUB patients with endoscopic confirmation of the following ICD-9-CM diagnoses for the first time after January 1, 2000, were identified: 531.0; 531.2; 531.4; 531.6 (gastric ulcer with hemorrhages); 532.0; 532.2; 532.4; 532.6 (duodenal ulcer with hemorrhages); 533.0; 533.2; 533.4; and 533.6 (nonspecific peptic ulcer with hemorrhages). Patients under the age of 20 years, and patients with prior gastrectomies or vagotomies were excluded. We excluded patients who were diagnosed with gastric cancer or Zollinger-Ellison syndrome between January 1, 1997, and the index date of our study. Pa-

One million $\mathrm{NHI}$ beneficiaries, representing approximately $5 \%$ of all enrollees in 2000

2000-2010

Based on inpatient discharge records, the PUB patients with endoscopic confirmation $(n=12,686)$

Using a triple or quadruple therapy that consists of PPIs, clarithromycin or tetracycline, amoxicillin or metronidazole, and bismuth or no bismuth $(n=2,463)$

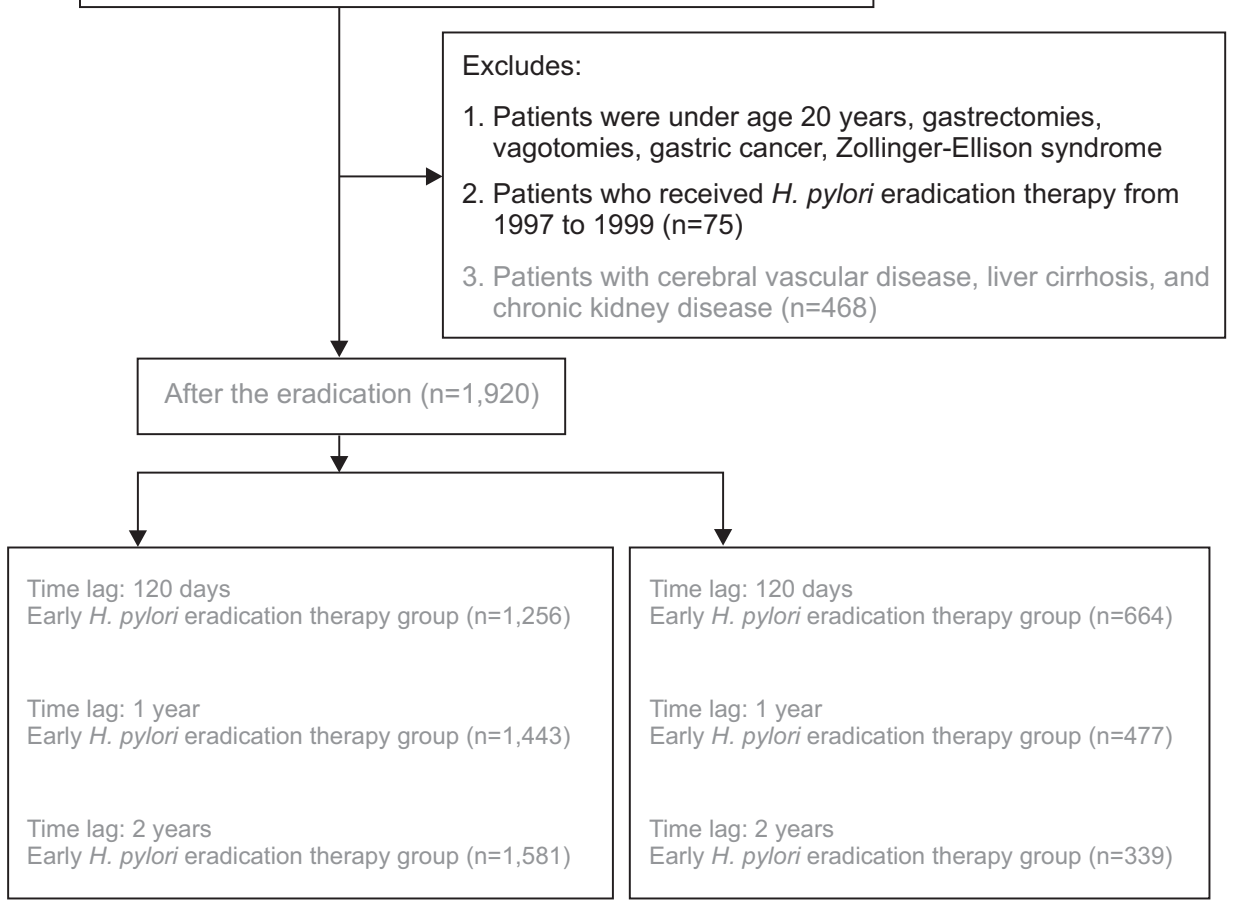

Fig. 1. Flowchart depicting participant selection.

NHI, National Health Insurance; PUB, peptic ulcer bleeding; PPI, proton pump inhibitor; $H$. pylori, Helicobacter pylori. 
tients who received $H$. pylori eradication therapy between 1997 and 1999 were also excluded. Patients with cerebral vascular disease (CVD), liver cirrhosis (LC), and chronic kidney disease (CKD) showed significantly higher rehospitalization rate. In addition, there is a correlation between coexisting diseases and complicated recurrent peptic ulcers. Therefore, patients with CVD, LC, and CKD were excluded. Fig. 1 shows a flow chart containing the total patients included.

\section{Definitions of early and late $\boldsymbol{H}$. pylori eradication groups}

According to the reimbursement policy of the NHI, patients with an endoscopically confirmed diagnosis of peptic ulcers and concurrent laboratory verification of $H$. pylori infection are reimbursed for 7 to 14 days of the $H$. pylori eradication therapy. The diagnosis of $H$. pylori infection in our study participants had been based on the results of a rapid urease test (RUT) or histological assessment using hematoxylin and eosin (H\&E) staining. Measuring from the time of PUB diagnosis to the $H$. pylori eradication therapy, we classified patients as being either in the early $H$. pylori eradication therapy group (time lag $\leq 120$ days after peptic ulcer diagnosis), or in the late $H$. pylori eradication therapy group (time lag $>120$ days after peptic ulcer diagnosis). ${ }^{12}$ However the definition of time lag is arbitrary; therefore, we also analyzed the effects of time lag more than 1 year ${ }^{13}$ and more than 2 years. The $H$. pylori eradication therapy using a triple or quadruple therapy that consists of proton pump inhibitors (PPIs), clarithromycin or tetracycline, amoxicillin or metronidazole, and bismuth or no bismuth.

\section{Definition of gastroduodenal ulcer history}

All endoscopically diagnosed gastroduodenal ulcers in patients from 1997 to the claim date of first PUB, based on ambulatory care and inpatient discharge records, are defined as having gastroduodenal ulcer history.

\section{Patient characteristics}

We recorded the age and sex of the patients. The locations of the endoscopically diagnosed PUB in each patient were recorded as gastric (531.0; 531.2; 531.4; 531.6), duodenal (532.0; 532.2; 532.4; 532.6), or nonspecific (533.0; 533.2; 533.4; 533.6). Patients were defined as users of PPIs, $\mathrm{H}_{2}$-blockers, aspirin, NSAIDs, cyclooxygenase-2 (COX-2) specific inhibitors, steroids, clopidogrel, ticlopidine, and warfarin based on whether they had used at least one prescription of the respective medication within 28 days of the end date of the early or late $H$. pylori eradication therapy period.

Conditions that required inpatient care or three or more ambulatory-care visits between January 1, 1997, and the index date of our study were defined as comorbidities. The comorbidities identified in our cohort and the corresponding ICD-9-CM diagnosis codes were as follows: diabetes mellitus (DM) ICD-9CM: 250; congestive heart failure (CHF) ICD-9-CM: 428; coro- nary artery disease (CAD) ICD-9-CM: 410-414; CVD ICD-9-CM: 430-438; chronic obstructive pulmonary disease (COPD) ICD9-CM: 491-492, 494, and 496; LC ICD-9-CM: 571.2, 571.5, and 571.6; and CKD ICD-9-CM: 580-589, 250.4, 274.1, 283.11, 403. x1, 404.x2, 404.x3, 440.1, 442.1, 447.3, 572.4, 642.1x, 646.2x, and 794.4

\section{Endpoint}

Based on inpatient discharge records, rehospitalization for complicated recurrent peptic ulcers with hemorrhages and/or perforations following endoscopic confirmation after $H$. pylori eradication between 2000 and 2010 were defined using the following ICD-9-CM codes: 531.0; 531.1; 531.2; 531.4; 531.5; 531.6 ; 532.0; 532.1; 532.2; 532.4; 532.5; 532.6; 533.0; 533.1; $533.2 ; 533.4 ; 533.5$; and 533.6.

\section{Statistical analysis}

Demographic data were expressed as categorical data and mean \pm standard deviation. The data for categorical variables are presented as percentages. We compared the differences between the early and late $H$. pylori eradication therapy groups using a chi-square analysis. We calculated the hazard ratios (HR) based on a 95\% confidence interval (CI) using a multivariate Cox regression analysis to compare the risk of rehospitalization for complicated recurrent peptic ulcers between the early and late $H$. pylori eradication therapy groups. A p-value less than 0.05 was considered to indicate a statistically significant relationship. All statistical analyses were performed using the SAS statistical package version 9.2 (SAS Institute, Cary, NC, USA).

\section{RESULTS}

The early and late $H$. pylori eradication therapy groups consisted of 1,256 and 664 PUB patients in time lag 120 days, respectively. The demographic data are presented in Table 1 . A significantly lower percentage of patients in the early $H$. pylori eradication therapy group used PPIs or H2-blockers $(\mathrm{p}<0.001)$, and NSAIDs $(\mathrm{p}<0.001)$, than patients in the late $H$. pylori eradication therapy group. The average follow-up duration is $5.47 \pm 3.22$ years in early $H$. pylori eradication therapy and $3.93 \pm 3.22$ years in late $H$. pylori eradication therapy (Table 1).

\section{Combined effects of $\boldsymbol{H}$. pylori eradication therapy and NSAID use for complicated peptic ulcers}

After adjusting for possible confounders, the results from Cox proportional hazards model analysis indicated that the late $H$. pylori eradication therapy group had a higher rate for complicated recurrent peptic ulcers (HR, 1.52; 95\% CI, 1.13 to 2.04; $\mathrm{p}=0.006$, in time lag more than 120 days (Table 2), HR, 1.20; $95 \%$ CI, 0.87 to $1.66 ; \mathrm{p}=0.275$, in time lag more than 1 year (Table 3), and HR, $1.10 ; 95 \%$ CI, 0.75 to $1.62 ; p=0.621$, in time lag more than 2 years (Table 3), compared with the early $H$. pylori 
Table 1. Different Characteristics of Peptic Ulcer Bleeding Patients with Helicobacter pylori Eradication within 120 Days and after 120 Days of the Initial Diagnosis

\begin{tabular}{|c|c|c|c|}
\hline Variable & $\begin{array}{c}\text { Early } \leq 120 \\
\text { days }\end{array}$ & $\begin{array}{c}\text { Late }>120 \\
\text { days }\end{array}$ & $\mathrm{p}$-value \\
\hline No. of patients & 1,256 & 664 & \\
\hline Age, yr & & & 0.065 \\
\hline $20-49$ & 469 (37.34) & $227(34.19)$ & \\
\hline $50-69$ & $518(41.24)$ & $264(39.76)$ & \\
\hline$\geq 70$ & $269(21.42)$ & $173(26.05)$ & \\
\hline Sex & & & 0.461 \\
\hline Male & $884(70.38)$ & 478 (71.99) & \\
\hline Female & $372(29.62)$ & $186(28.01)$ & \\
\hline Rehospitalization* & & & $<0.001$ \\
\hline No & $1,153(91.80)$ & $573(86.30)$ & \\
\hline Complicated $^{\dagger}$ & $103(8.20)$ & $91(13.70)$ & \\
\hline \multicolumn{4}{|l|}{ Comorbidities } \\
\hline DM & $154(12.26)$ & $107(16.11)$ & 0.019 \\
\hline $\mathrm{CHF}$ & $34(2.71)$ & $20(3.01)$ & 0.701 \\
\hline $\mathrm{CAD}$ & 167 (13.30) & $112(16.87)$ & 0.035 \\
\hline COPD & $146(11.62)$ & $92(13.86)$ & 0.158 \\
\hline Gastroduodenal ulcer history & $74(5.89)$ & $56(8.43)$ & 0.035 \\
\hline Ulcer position & & & $<0.001$ \\
\hline Gastric ulcer & $511(40.68)$ & $351(52.86)$ & \\
\hline Duodenal ulcer & 728 (57.96) & $298(44.88)$ & \\
\hline Peptic ulcer ${ }^{\ddagger}$ & $17(1.35)$ & $15(2.26)$ & \\
\hline \multicolumn{4}{|l|}{ Medication } \\
\hline PPIs or $\mathrm{H}_{2}$-blockers & $110(8.76)$ & $124(18.67)$ & $<0.001$ \\
\hline Aspirin & $67(5.33)$ & $31(4.67)$ & 0.528 \\
\hline NSAIDs & $184(14.65)$ & $145(21.84)$ & $<0.001$ \\
\hline COX-2 specific inhibitors & $46(3.66)$ & 39 (5.87) & 0.025 \\
\hline Steroids & $52(4.14)$ & $36(5.42)$ & 0.202 \\
\hline Clopidogrel & $20(1.59)$ & $12(1.81)$ & 0.727 \\
\hline Ticlopidine & $9(0.72)$ & $6(0.90)$ & 0.658 \\
\hline Warfarin & $4(0.32)$ & $3(0.45)$ & 0.645 \\
\hline Follow-up year & $5.47 \pm 3.22$ & $3.93 \pm 2.83$ & \\
\hline
\end{tabular}

Data are presented as number (\%) or mean \pm SD.

$\mathrm{DM}$, diabetes mellitus; $\mathrm{CHF}$, congestive heart failure; $\mathrm{CAD}$, cardiovascular disease; COPD, chronic obstructive pulmonary disease; PPIs, proton pump inhibitors; $\mathrm{H}_{2}$-blockers, histamine receptor-2 blockers; NSAIDs, nonsteroidal anti-inflammatory drugs; COX-2, cyclooxygenase-2.

*Rehospitalization for recurrent peptic ulcers; ${ }^{\dagger}$ Rehospitalization for complicated recurrent peptic ulcers with hemorrhages and perforations; ${ }^{\ddagger}$ Including gastric ulcer and duodenal ulcer.

eradication therapy group. On stratified analysis according to NSAID use, patients not receiving NSAIDs in the late $H$. pylori eradication therapy group was not associated with a higher risk for complicated recurrent peptic ulcers in time lag more than 120 days (HR, 1.33; 95\% CI, 0.88 to $1.99 ; \mathrm{p}=0.176$ ), in time lag
Table 2. Multivariate Cox Regression of Rehospitalization for Complicated Recurrent Peptic Ulcers with a Time Lag of More than 120 Days in the Overall Study Group

\begin{tabular}{|c|c|c|c|}
\hline Variable & HR & $95 \% \mathrm{CI}$ & p-value \\
\hline \multicolumn{4}{|l|}{ Time to H. pylori eradication* } \\
\hline$>120$ days vs $\leq 120$ days & 1.52 & $1.13-2.04$ & 0.006 \\
\hline \multicolumn{4}{|l|}{ Age, yr } \\
\hline $20-49$ vs $\geq 70$ & 0.23 & $0.15-0.35$ & $<0.001$ \\
\hline $50-69$ vs $\geq 70$ & 0.44 & $0.32-0.62$ & $<0.001$ \\
\hline \multicolumn{4}{|l|}{ Sex } \\
\hline Male vs female & 1.25 & $0.91-1.73$ & 0.167 \\
\hline Gastroduodenal ulcer history & 1.40 & $0.89-2.22$ & 0.149 \\
\hline \multicolumn{4}{|l|}{ Ulcer position } \\
\hline Gastric ulcer vs duodenal ulcer & 1.40 & $1.03-1.89$ & 0.031 \\
\hline Peptic ulcer $^{\dagger}$ vs duodenal ulcer & 0.86 & $0.29-2.51$ & 0.782 \\
\hline \multicolumn{4}{|l|}{ Comorbidities } \\
\hline $\mathrm{DM}$ & 1.06 & $0.71-1.58$ & 0.782 \\
\hline $\mathrm{CHF}$ & 0.75 & $0.29-1.91$ & 0.542 \\
\hline CAD & 1.05 & $0.72-1.55$ & 0.788 \\
\hline COPD & 0.84 & $0.57-1.24$ & 0.375 \\
\hline \multicolumn{4}{|l|}{ Medications } \\
\hline PPIs or $\mathrm{H}_{2}$-blockers & 2.30 & $1.65-3.19$ & $<0.001$ \\
\hline Aspirin & 0.50 & $0.26-0.93$ & 0.029 \\
\hline NSAIDs & 4.18 & $3.12-5.59$ & $<0.001$ \\
\hline COX-2 specific inhibitors & 2.63 & $1.72-4.04$ & $<0.001$ \\
\hline Steroids & 0.68 & $0.37-1.24$ & 0.209 \\
\hline Clopidogrel & 0.85 & $0.31-2.36$ & 0.753 \\
\hline Ticlopidine & 0.37 & $0.05-2.71$ & 0.326 \\
\hline Warfarin & 3.67 & $0.82-16.51$ & 0.090 \\
\hline
\end{tabular}

HR, hazard ratio; CI, confidence interval; DM, diabetes mellitus; CHF, congestive heart failure; $\mathrm{CAD}$, cardiovascular disease; $\mathrm{COPD}$, chronic obstructive pulmonary disease; PPIs, proton pump inhibitors; $\mathrm{H}_{2}-$ blockers, histamine receptor-2 blockers; NSAIDs, nonsteroidal antiinflammatory drugs; COX-2, cyclooxygenase-2.

*Time of peptic ulcer diagnosis to the Helicobacter pylori eradication therapy; ${ }^{\dagger}$ Peptic ulcer includes gastric ulcer and duodenal ulcer.

more than 1 year (HR, 1.30; 95\% CI, 0.82 to 2.07 ; $\mathrm{p}=0.264$ ), and in time lag more than 2 years (HR,1.20; 95\% CI, 0.69 to 2.07; $\mathrm{p}=0.523$ ) (Fig. 2).

\section{Relative risk of complicated peptic ulcers}

The Cox proportional hazards analysis identified the patients who were 20 to 49 years of age (HR, 0.23 ; 95\% CI, 0.15 to 0.35 ; $\mathrm{p}<0.001)$ or 50 to 69 years of age $(\mathrm{HR}, 0.44 ; 95 \% \mathrm{CI}, 0.32$ to 0.62 ; $\mathrm{p}<0.001$ ) had a significantly lower risk for complicated recurrent peptic ulcers, compared with the patients who were 70 years of age and older. In addition, gastric ulcer (HR, 1.40; 95\% CI, 1.03 to $1.89 ; \mathrm{p}=0.031$ ), PPIs or $\mathrm{H}_{2}$-blockers (HR, 2.30; 95\% CI, 1.65 to $3.19 ; \mathrm{p}<0.001$ ), NSAIDs (HR, 4.18 ; $95 \%$ CI, 3.12 to 5.59 ; $\mathrm{p}<0.001)$, and COX-2 specific inhibitors (HR, 2.63; 95\% CI, 1.72 


\section{Subgroup}

Number

$>120$ days vs $\leq 120$ days

NSAIDs use

$\begin{array}{lr}\text { Yes } & 329 \\ \text { No } & 1591\end{array}$

$>1 \mathrm{yr}$ vs $\leq 1 \mathrm{yr}$

NSAIDs use

Yes

No

329

1,591

$>2 \mathrm{yr}$ vs $\leq 2 \mathrm{yr}$

NSAIDs use

Yes

329

No

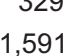

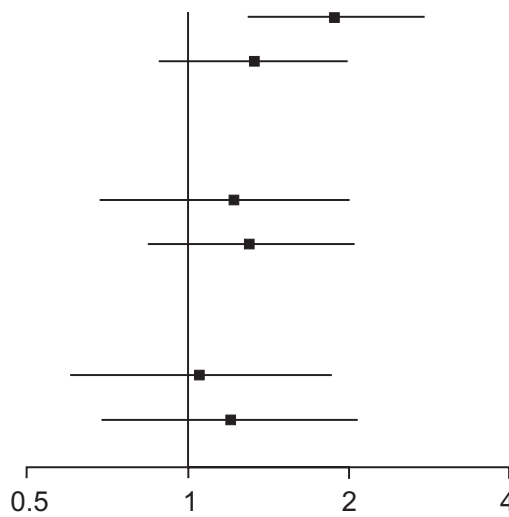

Hazard ratio $(95 \% \mathrm{Cl})$

$1.88(1.18-2.99)$

$1.33(0.88-1.99)$

$1.22(0.76-1.96)$

$1.30(0.82-2.07)$

$1.05(0.60-1.85)$

$1.20(0.69-2.07)$
Fig. 2. Multivariate stratified Cox proportional hazards model analysis for predicting rehospitalization in patients with complicated recurrent peptic ulcers according to nonsteroidal anti-inflammatory drug (NSAID) use (adjusted for all other factors). CI, confidence interval.

Table 3. Multivariate Cox Regression of Rehospitalization for Complicated Recurrent Peptic Ulcers with Time Lags of More than 1 Year and 2 Years in the Overall Study Group

\begin{tabular}{|c|c|c|c|c|c|c|}
\hline Variable & $\mathrm{HR}$ & $95 \% \mathrm{CI}$ & p-value & $\mathrm{HR}$ & $95 \% \mathrm{CI}$ & p-value \\
\hline \multicolumn{7}{|l|}{ Time to H. pylori eradication* } \\
\hline$>1 \mathrm{yr}$ vs $\leq 1 \mathrm{yr}$ & 1.20 & $0.87-1.66$ & 0.275 & - & - & - \\
\hline$>2 \mathrm{yr} v s \leq 2 \mathrm{yr}$ & - & - & - & 1.10 & $0.75-1.62$ & 0.621 \\
\hline \multicolumn{7}{|l|}{ Age } \\
\hline $20-49$ vs $\geq 70$ & 0.23 & $0.15-0.36$ & $<0.001$ & 0.23 & $0.15-0.36$ & $<0.001$ \\
\hline $50-69$ vs $\geq 70$ & 0.44 & $0.32-0.61$ & $<0.001$ & 0.45 & $0.32-0.62$ & $<0.001$ \\
\hline \multicolumn{7}{|l|}{ Sex } \\
\hline Male vs female & 1.29 & $0.94-1.78$ & 0.121 & 1.31 & $0.95-1.80$ & 0.103 \\
\hline Gastroduodenal ulcer history & 1.47 & $0.93-2.32$ & 0.100 & 1.47 & $0.93-2.33$ & 0.097 \\
\hline \multicolumn{7}{|l|}{ Ulcer position } \\
\hline Gastric ulcer vs duodenal ulcer & 1.47 & $1.09-1.99$ & 0.012 & 1.49 & $1.10-2.02$ & 0.010 \\
\hline Peptic ulcer ${ }^{\dagger}$ vs duodenal ulcer & 0.85 & $0.29-2.49$ & 0.766 & 0.86 & $0.29-2.53$ & 0.776 \\
\hline \multicolumn{7}{|l|}{ Comorbidities } \\
\hline $\mathrm{DM}$ & 1.06 & $0.71-1.57$ & 0.795 & 1.05 & $0.70-1.56$ & 0.824 \\
\hline CHF & 0.74 & $0.29-1.88$ & 0.520 & 0.73 & $0.29-1.87$ & 0.516 \\
\hline CAD & 1.07 & $0.73-1.57$ & 0.741 & 1.08 & $0.74-1.58$ & 0.699 \\
\hline COPD & 0.84 & $0.56-1.24$ & 0.369 & 0.83 & $0.56-1.23$ & 0.344 \\
\hline \multicolumn{7}{|l|}{ Medication } \\
\hline PPIs or $\mathrm{H}_{2}$-blockers & 2.38 & $1.71-3.31$ & $<0.001$ & 2.41 & $1.73-3.35$ & $<0.001$ \\
\hline Aspirin & 0.49 & $0.26-0.92$ & 0.027 & 0.49 & $0.26-0.92$ & 0.027 \\
\hline NSAIDs & 4.22 & $3.15-5.66$ & $<0.001$ & 4.27 & $3.19-5.71$ & $<0.001$ \\
\hline COX-2 specific inhibitors & 2.67 & $1.73-4.12$ & $<0.001$ & 2.74 & $1.78-4.21$ & $<0.001$ \\
\hline Steroid & 0.72 & $0.40-1.32$ & 0.290 & 0.71 & $0.39-1.30$ & 0.267 \\
\hline Clopidogrel & 0.83 & $0.30-2.29$ & 0.712 & 0.82 & $0.29-2.27$ & 0.698 \\
\hline Ticlopidine & 0.36 & $0.05-2.65$ & 0.315 & 0.36 & $0.05-2.64$ & 0.313 \\
\hline Warfarin & 3.82 & $0.84-17.30$ & 0.083 & 3.82 & $0.83-17.51$ & 0.085 \\
\hline
\end{tabular}

HR, hazard ratio; CI, confidence interval; DM, diabetes mellitus; CHF, congestive heart failure; CAD, cardiovascular disease; COPD, chronic obstructive pulmonary disease; PPIs, proton pump inhibitors; $\mathrm{H}_{2}$-blockers, histamine receptor-2 blockers; NSAIDs, nonsteroidal anti-inflammatory drugs; COX-2, cyclooxygenase-2.

*Time of peptic ulcer diagnosis to the Helicobacter pylori eradication therapy; ${ }^{\dagger}$ Peptic ulcer includes gastric ulcer and duodenal ulcer. 
to $4.04 ; \mathrm{p}<0.001)$ as independent risk factors for complicated recurrent peptic ulcers. Patients receiving aspirin had a lower risk for complicated recurrent peptic ulcer (HR, 0.50; 95\% CI, 0.26 to 0.93; $\mathrm{p}=0.029$ ) (Table 2).

\section{DISCUSSION}

The timing of eradication is an important issue. We defined the late $H$. pylori eradication therapy group as those patients for whom therapy was delayed by more than 120 days and obtained the late $H$. pylori eradication therapy increased the risk of complicated recurrent peptic ulcers in PUB patients (HR, 1.52; 95\% CI, 1.13 to 2.04; $\mathrm{p}=0.006)$. However the definition of time lag is arbitrary; therefore, we also analyzed the effects of time lag more than 1 year $^{13}$ and more than 2 years and obtained the similar risk of complicated recurrent peptic ulcers in PUB patients for time lag more than 1 year (HR, 1.20; 95\% CI, 0.87 to $1.66 ; \mathrm{p}=0.275)$ and time lag more than 2 years (HR, 1.10; 95\% CI, 0.75 to $1.62 ; \mathrm{p}=0.621$ ) (Tables 2 and 3). Our data indicated H. pylori eradication within 120 days was associated with decreased complicated recurrent peptic ulcers in PUB patients. $H$. pylori eradication treatment should be started within 120 days in cases of bleeding ulcer. Acute PUB patients frequently test negative $H$. pylori infection. Delaying treatment to after discharge leads to reduced compliance or loss to follow-up without receiving treatment. We must increase patient compliance to avoid loss to follow-up. Physicians should check the H. pylori status of patients, and initiate eradication therapy for patients who test positive within 120 days in PUB patients.

Cameron et al. ${ }^{14}$ reported an $H$. pylori reinfection rate of approximately $0.4 \%$. In our study, the results for PUB patients in the early and late $H$. pylori-eradication therapy groups indicated that the $H$. pylori had persisted in their stomach mucosa before the eradication therapy was initiated. The results of our nationally representative observational study reflect that the actual conditions of $35.1 \%$ of $H$. pylori-positive peptic ulcer patients are not initially treated with eradication therapy. The number and site of gastric biopsies may contribute to heterogeneity in H. pylori detection. ${ }^{15,16}$ PUB patients had higher false-negative results for $H$. pylori diagnostic testing. ${ }^{7}$ Moreover, the need for expedient intervention during endoscopic examination of hemodynamically unstable and intolerable patients may not allow the time required to determine their $H$. pylori status. ${ }^{17}$ These reasons explain the delayed diagnosis of $H$. pylori positive peptic ulcers.

Gastroprotective agents such as $\mathrm{H}_{2}$-blockers and PPIs are lower in cost: most cost less than US \$0.25 and \$0.8 per tablet, respectively. Therefore, participants in early and late $H$. pylori eradication therapy group were receiving prophylactic PPIs or $\mathrm{H}_{2}$-blockers (8.76\% vs 18.67\%, $\mathrm{p}<0.001$ ) (Table 1). These patients may have higher risk of PUB by physicians' decisions. Moreover, our data showed there is higher risk of complicated recurrent peptic ulcer in patients using PPIs or $\mathrm{H}_{2}$-blockers (HR, 2.30; 95\% CI, 1.65 to 3.19; $\mathrm{p}<0.001$ ) (Table 2).

There are limitations to our findings. First, there were no confirmations of the $H$. pylori status of our participants following eradication therapy. The reality is that this may change over time, especially in the context of rising bacterial resistance. However, a latest multicenter study in Taiwan ${ }^{18}$ reported a PPIbased $H$. pylori eradication rate of approximately $87.1 \%$. The $H$. pylori eradication rates, which is PPI-based $H$. pylori eradication therapy, are also similar in cirrhotic patients $(81.8 \%)^{19}$ and endstage renal disease patients $(81.2 \%),{ }^{20}$ Our study only enrolled PUB patients using PPI-based $H$. pylori eradication therapy; moreover, both cohorts in our study were enrolled from the same population and the same time. In addition, we obtained lower second $H$. pylori eradication rate $5.97 \%(75 / 1,256)$ in early group and 7.08\% (47/664) in late group during the 11year period (data not shown). Therefore, the eradication failure rates in our early and late $H$. pylori eradication therapy groups should have been similar and should not have significantly influenced our results. Second, differences in physician behavior and admission criteria for peptic ulcers were also potential confounders for our study. However, we only analyzed the risk of rehospitalization for endoscopically confirmed complicated recurrent peptic ulcers in PUB patients to limit the influence of such subjective factors on our results. Lastly, testing for $H$. pylori is affected by concomitant medications such as NSAIDs, aspirin, or PPIs. Moreover, there is not uniformity in the diagnostic tests between RUT or a histological assessment using H\&E staining. Because we only address our endpoint over the complicated recurrent peptic ulcer episode after early and late $H$. pylori eradication therapy, these limitations were unlikely to bias our results.

In summary, our real-world data showed that only 2,463 patients receiving $H$. pylori eradication in 12,686 PUB hospitalized patients. Other than NSAIDs use, ${ }^{10}$ idiopathic peptic ulcer, and comorbidities $^{21,22}$ related $H$. pylori negative peptic ulcers, most PUB patients delayed $H$. pylori diagnostic testing and eradication therapy, which is unlikely aggressive $H$. pylori testing and eradication in prospective study or guideline recommendation. ${ }^{23,24}$ These patients did not receive re-endoscopy examination or ${ }^{13} \mathrm{C}$-urea breath test to reconfirm $H$. pylori status when these were initially $H$. pylori negative by diagnostic testing.

In conclusion, our study showed that $H$. pylori eradication within 120 days was associated with decreased complicated recurrent peptic ulcers in PUB patients. Thus, we recommend $H$. pylori eradication should be carried out within 120 days in PUB patients.

\section{CONFLICTS OF INTEREST}

No potential conflict of interest relevant to this article was reported. 


\section{ACKNOWLEDGEMENTS}

We wish to thank the Taiwan Ministry of Education for their support for this work through its "Aim for the Top University Plan." We would like to thank the Bureau of National Health Insurance and the NHRI for making the NHIRD available to us for this study.

\section{REFERENCES}

1. Laine L, Peterson WL. Bleeding peptic ulcer. N Engl J Med 1994;331:717-727.

2. NIH Consensus Conference. Helicobacter pylori in peptic ulcer disease. NIH Consensus Development Panel on Helicobacter pylori in Peptic Ulcer Disease. JAMA 1994;272:65-69.

3. Chen TS, Luo JC, Chang FY. Prevalence of Helicobacter pylori infection in duodenal ulcer and gastro-duodenal ulcer diseases in Taiwan. J Gastroenterol Hepatol 2010;25:919-922.

4. Hopkins RJ, Girardi LS, Turney EA. Relationship between Helicobacter pylori eradication and reduced duodenal and gastric ulcer recurrence: a review. Gastroenterology 1996;110:1244-1252.

5. Sanchez-Delgado J, Gene E, Suarez D, et al. Has H. pylori prevalence in bleeding peptic ulcer been underestimated? A metaregression. Am J Gastroenterol 2011;106:398-405.

6. Lee JM, Breslin NP, Fallon C, O'Morain CA. Rapid urease tests lack sensitivity in Helicobacter pylori diagnosis when peptic ulcer disease presents with bleeding. Am J Gastroenterol 2000;95:11661170.

7. Gisbert JP, Abraira V. Accuracy of Helicobacter pylori diagnostic tests in patients with bleeding peptic ulcer: a systematic review and meta-analysis. Am J Gastroenterol 2006;101:848-863.

8. Hermansson M, Ekedahl A, Ranstam J, Zilling T. Decreasing incidence of peptic ulcer complications after the introduction of the proton pump inhibitors, a study of the Swedish population from 1974-2002. BMC Gastroenterol 2009;9:25.

9. Hippisley-Cox J, Coupland C, Logan R. Risk of adverse gastrointestinal outcomes in patients taking cyclo-oxygenase-2 inhibitors or conventional non-steroidal anti-inflammatory drugs: population based nested case-control analysis. BMJ 2005;331:13101316.

10. McColl KE. How I manage H. pylori-negative, NSAID/aspirinnegative peptic ulcers. Am J Gastroenterol 2009;104:190-193.

11. Cheng SH, Chiang TL. The effect of universal health insurance on health care utilization in Taiwan. Results from a natural experi- ment. JAMA 1997;278:89-93.

12. Nozaki K, Shimizu N, Ikehara Y, et al. Effect of early eradication on Helicobacter pylori-related gastric carcinogenesis in Mongolian gerbils. Cancer Sci 2003;94:235-239.

13. Wu CY, Kuo KN, Wu MS, Chen YJ, Wang CB, Lin JT. Early Helicobacter pylori eradication decreases risk of gastric cancer in patients with peptic ulcer disease. Gastroenterology 2009;137:16411648.

14. Cameron EA, Bell GD, Baldwin L, Powell KU, Williams SG. Longterm study of re-infection following successful eradication of Helicobacter pylori infection. Aliment Pharmacol Ther 2006;23:13551358.

15. Working Party of the European Helicobacter pylori Study Group. Technical annex: tests used to assess Helicobacter pylori infection. Gut 1997;41 Suppl 2:S10-S18.

16. Working Party of the European Helicobacter pylori Study Group. Guidelines for clinical trials in Helicobacter pylori infection. Gut 1997;41 Suppl 2:S1-S9.

17. Bianchi Porro G, Lazzaroni M. The conflicting relationship between Helicobacter pylori and non-steroidal anti-inflammatory drugs in peptic ulcer bleeding. Scand J Gastroenterol 1999;34:225228.

18. Liou JM, Chen CC, Chen MJ, et al. Sequential versus triple therapy for the first-line treatment of Helicobacter pylori: a multicentre, open-label, randomised trial. Lancet 2013;381:205-213.

19. Lo GH, Yu HC, Chan YC, et al. The effects of eradication of Helicobacter pylori on the recurrence of duodenal ulcers in patients with cirrhosis. Gastrointest Endosc 2005;62:350-356.

20. Tseng GY, Lin HJ, Fang CT, et al. Recurrence of peptic ulcer in uraemic and non-uraemic patients after Helicobacter pylori eradication: a 2-year study. Aliment Pharmacol Ther 2007;26:925-933.

21. Chang SS, Hu HY. Helicobacter pylori is not the predominant etiology for liver cirrhosis patients with peptic ulcer disease. Eur J Gastroenterol Hepatol 2013;25:159-165.

22. Kang JY, Ho KY, Yeoh KG, et al. Peptic ulcer and gastritis in uraemia, with particular reference to the effect of Helicobacter pylori infection. J Gastroenterol Hepatol 1999;14:771-778.

23. Chan FK, Sung JJ, Chung SC, et al. Randomised trial of eradication of Helicobacter pylori before non-steroidal anti-inflammatory drug therapy to prevent peptic ulcers. Lancet 1997;350:975-979.

24. Malfertheiner P, Megraud F, O'Morain CA, et al. Management of Helicobacter pylori infection: the Maastricht IV/ Florence Consensus Report. Gut 2012;61:646-664. 